\title{
Editorial
}

\section{Photovoltaic Materials and Devices 2017}

\author{
Bhushan Sopori $\mathbb{D}^{1},{ }^{1}$ Prakash Basnyat, ${ }^{2}$ and Srinivas Devayajanam $\mathbb{D D}^{2}$ \\ ${ }^{1}$ National Renewable Energy Laboratory, 21564 Shady Lane, Idledale, CO 80453, USA \\ ${ }^{2}$ New Jersey Institute of Technology, 138 Warren Street, University Heights, Newark, NJ 07102, USA
}

Correspondence should be addressed to Bhushan Sopori; bhushan.sopori@gmail.com

Received 26 October 2017; Accepted 26 October 2017; Published 19 April 2018

Copyright (C) 2018 Bhushan Sopori et al. This is an open access article distributed under the Creative Commons Attribution License, which permits unrestricted use, distribution, and reproduction in any medium, provided the original work is properly cited.

The demand of photovoltaic energy has continued to grow in recent years concomitant with a decrease in the module prices. There continues to be slight overcapacity of production despite large installations worldwide, particularly in China and the USA. The global capacity additions in 2017 are expected to reach 79 gigawatts $(\mathrm{GW})$, slightly higher than $77 \mathrm{GW}$ in 2016 . While most of the solar cell manufacturing is occurring in China, there is a growing interest in developing module assembly in many other countries (particularly in India). As the manufacturing volume grows, there is continued reduction in the manufacturing cost. However, there continues to be considerable need for further research into improved cell/module designs and fabrication technology. This is the 4th special issue of the International Journal of Photoenergy on "Photovoltaic Materials and Devices" and is a very short assembly of accepted papers from a much wider submission, aimed at recent advances in materials and PV systems. This issue contains 5 papers on various aspects of photovoltaics, which are briefly described here.

Research paper "Optical Tests on a Curve Fresnel Lens as Secondary Optics for Solar Troughs" by D. Fontani et al. reveals the development of curved Fresnel lens as a secondary concentrator for solar parabolic troughs used during solar thermal collection. Results for the accuracy of the realized shape of cylindrical Fresnel lens (CFL) based on optical characterization of various samples are also presented. The study and the tests have made possible to detect the criticality of the first CFL prototypes and they provide some precise indications of the possible implementation plans during the lens construction processes which can be considered as the main responsible factors for loss of optical lens performance.
The paper by O. K. Echendu et al. entitled "Characteristics of Nanocrystallite-CdS Produced by Low-Cost Electrochemical Technique for Thin Film Photovoltaic Application: The Influence of Deposition Voltage" presents electrodeposition of cadmium sulfide thin films at different cathodic growth voltages and characterization of the films before and after postdeposition heat treatment. Postdeposition annealing results in phase transformation which leaves the films with only the hexagonal crystal phase and reduced strain and dislocation density while increasing the crystallite sizes.

Article written by S.A. Amin et al. "The Effects of Interdot Spacing and Dot Size on the Performance of InGaAs/ GaAs QDIBSC" elucidates the wave behavior of charge carriers inside the dot and its barrier with varying dot size and interdot spacing. Based on the behavior of electron wave function, they found that changing the dot spacing leads to a change in the intermediate band (IB) width and in the density of states, whereas varying the size of dots leads to a formation of a second IB. Presented results suggest that multiple IBs can potentially improve the efficiency, if the widths and positions of the IBs are optimized.

Paper submitted by M. Ali et al. "Performance Investigation of Air Velocity Effects on PV Modules under Controlled Conditions" to this journal sheds light on the efficacy of air cooling on solar panels. An experimental investigation was carried using a wind tunnel and an artificial solar simulator. Change in surface temperature, power output, and efficiency of PV modules under different air velocity in different direction was studied. Thermal analysis of the modules is performed through ANSYS Fluent in which 
junction temperature and heat flux of modules are determined. Experiments helped in determining the optimum tilt angle with the incoming air flow to increase the performance parameters for both the (c-Si and poly $\mathrm{Si}$ ) modules.

K. Attari's paper "The Design and Optimization of GaAs Single Solar Cells Using the Genetic Algorithm and Silvaco ATLAS" proposes a cell structure with new buffer layer and the back surface filled (BSF) that can significantly improve the performance due to higher collection of photogenerated minority carriers. The work demonstrates the simulation based on MATLAB algorithm of a maximum output power solar cell and its optimization. Effect of doping densities, thickness of cell layers, and choice of materials on various cell parameters was monitored. Results suggest an improvement in the conversion efficiency of up to $29.7 \%$.

We hope that readers will enjoy this issue.

\section{Acknowledgments}

Special thanks are due to Nadine Abdelhay for her continued help in coordinating this issue.

Bhushan Sopori

Prakash Basnyat

Srinivas Devayajanam 

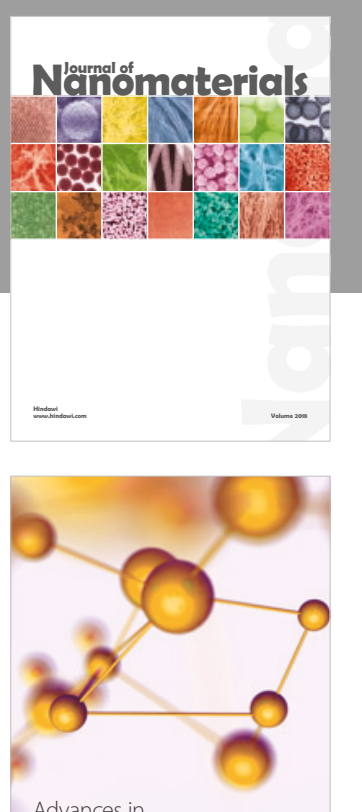

Physical Chemistry
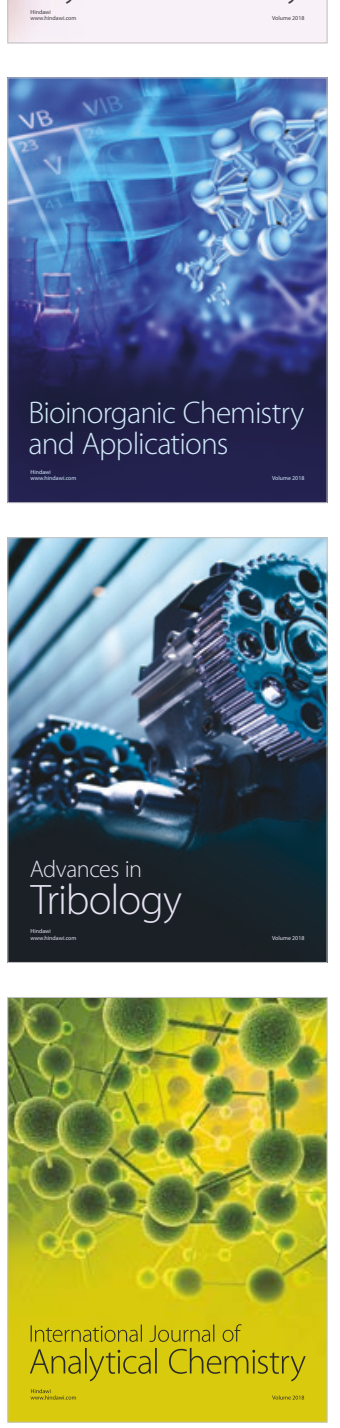

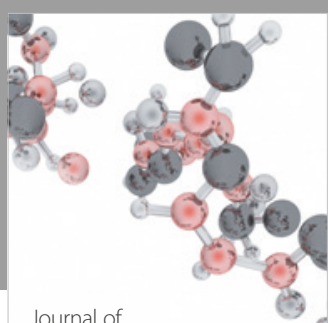

Analytical Methods

in Chemistry

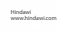

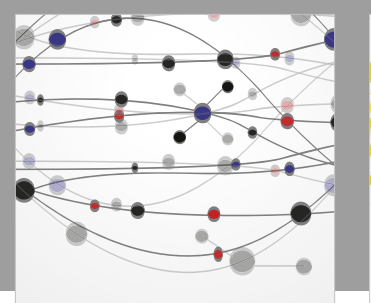

The Scientific World Journal

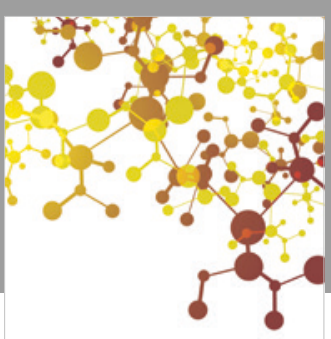

Journal of

Applied Chemistry
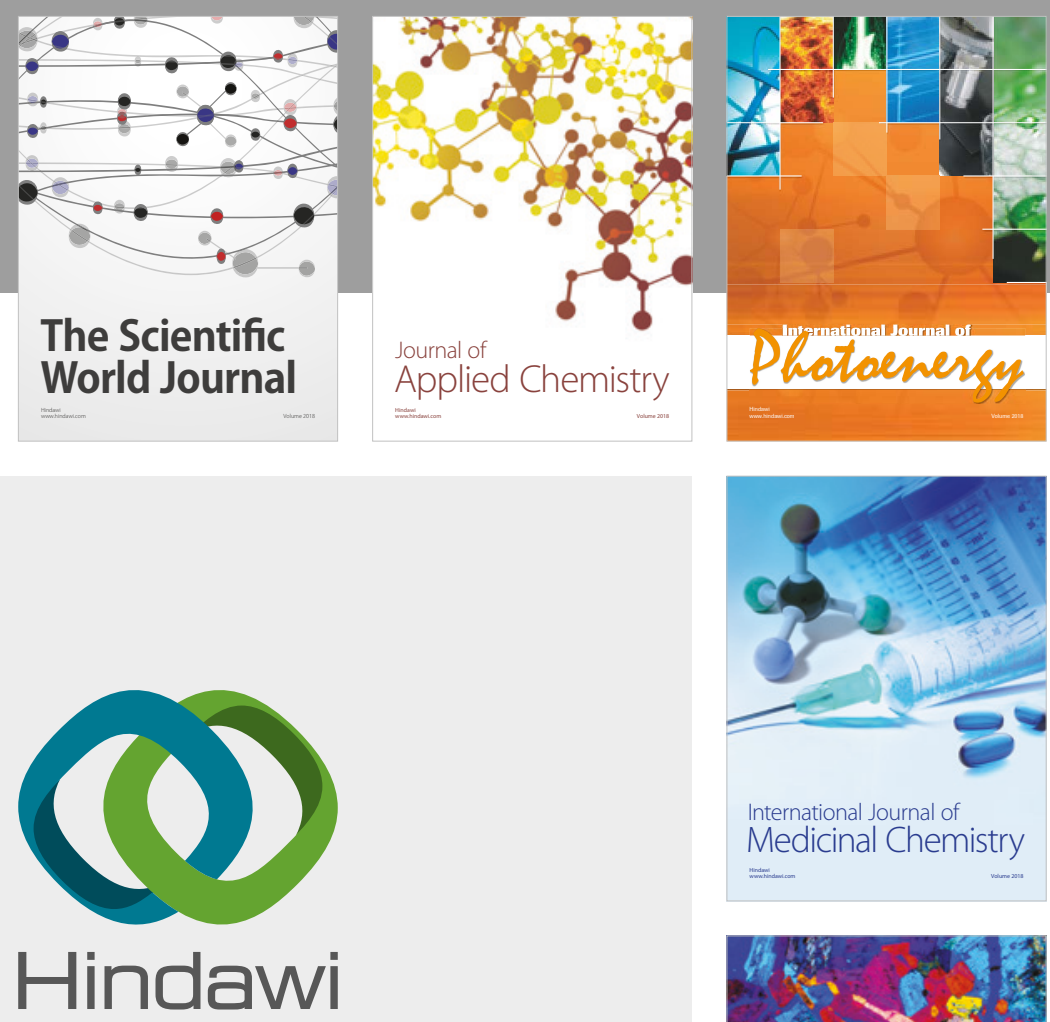

Submit your manuscripts at

www.hindawi.com
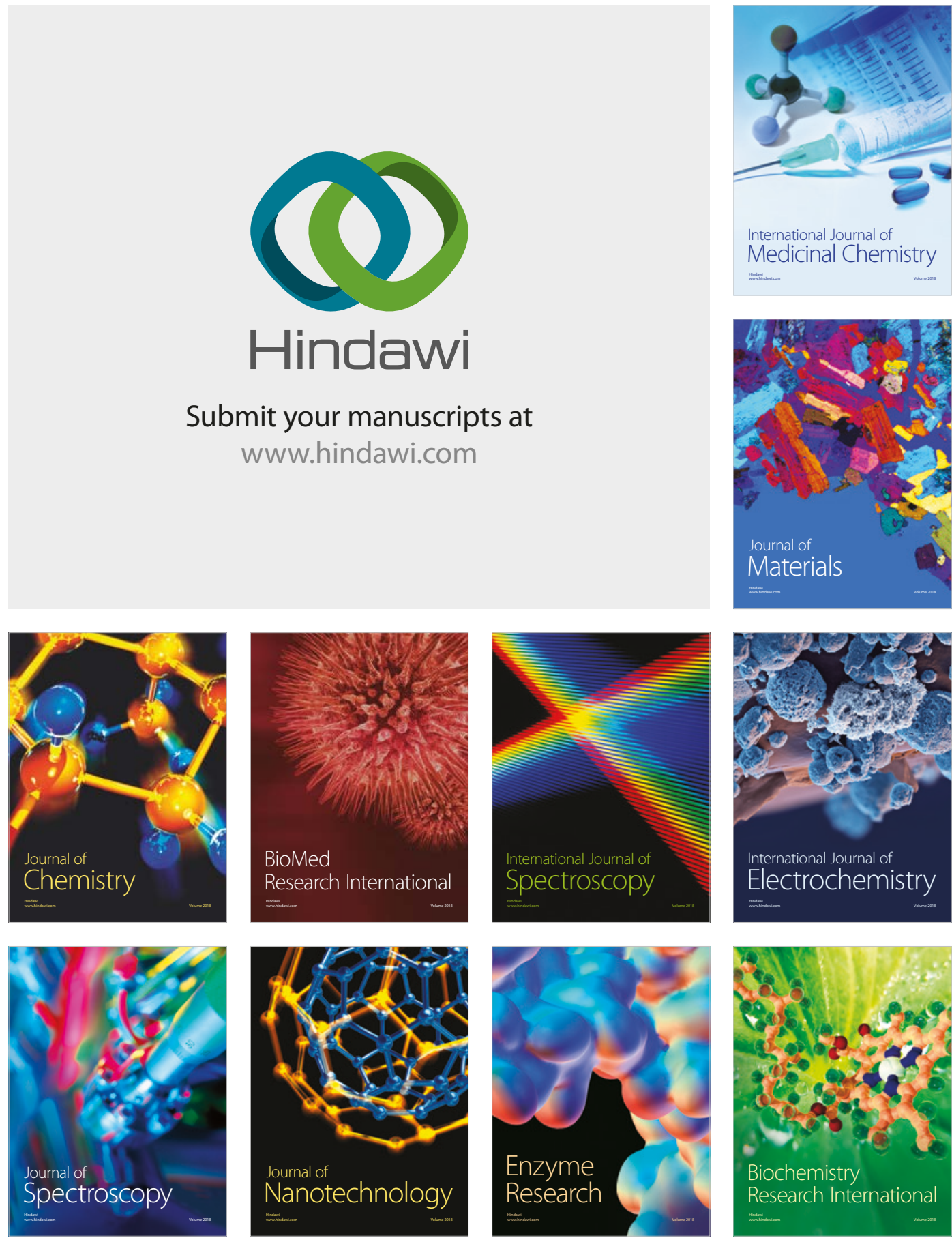
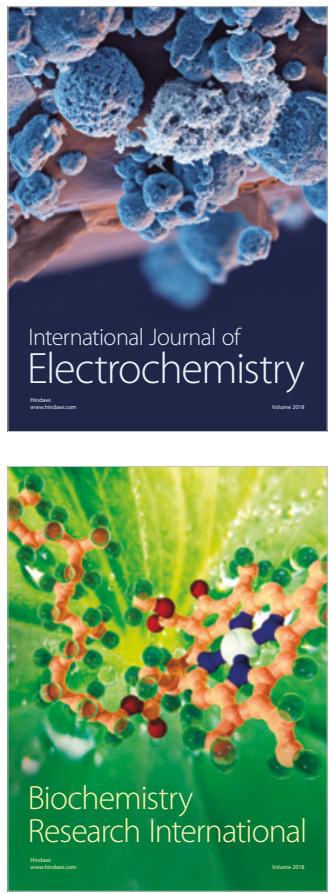